\section{Marrakesh: a centre for tortoise trade}

The Moroccan town of Marrakesh is an important cultural and tourist destination. Thousands of visitors each day shop in the historic walled medina, where, besides clothes, carpets, curios and other items, wildlife is openly offered for sale. One species commonly traded is the Vulnerable spur-thighed tortoise Testudo graeca. In Morocco the species suffers from the effects of habitat destruction and alteration, and increased road density, and is expected to be affected negatively by projected future climate change. Up until the late 1970s the species was legally exported from Morocco in the tens of thousands per year but since 1978 it has been included on the country's protected species list, precluding all international and domestic trade.

Znari et al. (2005, Journal of Arid Environments, 62, 55-74) collected data from 24 shops in Marrakesh in July-August 2001, recording 692 tortoises for sale; $63 \%$ were $<10 \mathrm{~cm}$ in length and only $3 \%$ were large $(\geq 18 \mathrm{~cm})$ individuals. It appeared to them that the older, larger tortoises had been removed in the past and that in the early 2000 s smaller tortoises were taken to meet the demand for the pet trade. We recently had the opportunity to visit Marrakesh and reassess its tortoise trade. During seven visits in May-June 2013, April-June and December 2014 we recorded a total of 820 tortoises for sale. Tortoises were present during each survey, with fewest in June 2013 (17 tortoises) and more in June 2014 (182 tortoises) and December 2014 (185 tortoises). No seasonal pattern was apparent. The total number of shops selling tortoises was 17 , with 3-14 having them on display at any given time. Typically vendors had small numbers on display, up to $10-12$ tortoises, but at least three shops regularly had $30-80$ tortoises in stock. All trade was open and no tortoises were kept hidden. As in 2001 the majority of spur-thighed tortoises were small and two-thirds were c. 4-10 cm in length, corresponding to ages of c. $2-8$ years. Circa $4 \%$ were large individuals, probably $>10$ years of age. Asking prices varied with size and between vendors but $4 \mathrm{~cm}$ tortoises could be bought for USD 1.00 and $13 \mathrm{~cm}$ tortoises for USD 7.50. The mean asking prices for tortoises in this size range increases in a linear fashion, starting at USD 6.50 and increasing by USD 0.65 for every $\mathrm{cm}$ increase in carapace length.

We conclude that little has changed in terms of the trade in spur-thighed tortoises in Marrakesh since 2001, with apparently similar volumes of similar age-classes entering the trade, which retains its openness in blatant disregard of the law. New protected species legislation was adopted by the Moroccan parliament in 2013 but has yet to be brought into effect. This new legislation should provide more clarity and allows for greater punitive measures for trading in protected animals. Once adopted we hope that this will allow a new start for stronger enforcement actions and ultimately end the open trade of spur-thighed tortoises in Marrakesh and elsewhere in Morocco.

Daniel Bergin, Molly Gray and Vincent Nijman Oxford Wildlife Trade Research Group, Oxford Brookes University, Oxford, UK. E-mailvnijman@brookes.ac.uk

\section{First camera-trap video evidence of the Amur tiger breeding in China}

Camera traps provide a non-invasive technique to monitor wildlife, especially cryptic species. A network of camera traps has been used to study carnivores in north-eastern China, during which footage of an Amur tiger Panthera tigris altaica and two cubs was filmed. This is the first time that camera-trap video evidence of the Amur tiger breeding in China has been obtained. Historically, the Amur tiger was distributed across most of the mountainous forest areas of north-east China, but it is believed there are now only c. 18-22 individuals, in Heilongiang and Jilin provinces. The main Amur tiger population lies in the Sikhote Alin region of Russia.

On 10 October 2014 a photograph of a female Amur tiger with a cub was obtained in Jincang forest farm, which is not within a protected area, by a local man who took the photograph with his mobile phone. Examination of the pugmarks confirmed the presence of a female and a cub. On 4 November 2014 a camera-trap video of a female Amur tiger with two cubs was captured in Wangqing National Nature Reserve in Xinancha forest farm after 1,945 trapdays. The location is a straight-line distance of c. $30 \mathrm{~km}$ from the Sino-Russian border. A study in Hunchun Nature reserve in Jilin province, to the south-east, during 2009-2011, detected one female and four male tigers, using non-invasive genetic techniques, indicating the potential for a small breeding group (Caragiulo et al., 2014, Oryx, http://dx.doi.org/10.1017/So030605314000817). In 2014 we documented the Amur tiger on 17 occasions (eight camera-trap records, two reports by local witnesses, three identifications of pug marks, and losses of livestock on four occasions) in 13 locations in north-east China. This work has shown that Amur tigers can be successfully photographed when signs of presence are carefully interpreted and camera-trap sites carefully selected.

The study in Wangqing is mainly funded by WWF, Jilin provincial forest department and the Fondation Prince Albert II de Monaco, and is also part of the Amur leopard transboundary scientific cooperation memorandum of understanding between the Russian United Administration of the State Nature Biosphere Reserves Kedrovaya Pad and the Land of the Leopard, and the administrations of Hunchun and Wangqing Nature Reserves. We thank 